\title{
Cake Dosage Form
}

National Cancer Institute

\section{Source}

National Cancer Institute. Cake Dosage Form. NCI Thesaurus. Code C68951.

A solid composed of active ingredient(s), excipients (usually electrolytes and bulking agents), and a solvent system which are lyophilized to yield a compressed solid with uniform ing redient distribution. The resulting lyophilized cake maintains its structure and stability over an extended period of time, and is intended for reconstitution prior to administration. 